\title{
Postdigital Living and Algorithms of Desire
}

\author{
Nataša Lacković ${ }^{1}$
}

Published online: 11 June 2020

(C) Springer Nature Switzerland AG 2020

Media hold a powerful grip over human life, influencing its various aspects such as (un)democratic decision-making (Berghel 2018), adolescents' life decisions (Ayers, Althouse, Leas, Dredze, and Allem 2017), and adoption of worldviews that put entire groups of people under the banner of mortal enemies (Mathew, Dutt, Goyal, and Mukherjee 2019). Many people are increasingly 'relying on their devices during this pandemic to inform and distract more than ever before, creating a huge opportunity for media companies to engage a captive audience' (Jones 2020). In our postdigital times of blurred boundaries between virtual and real (Jandrić et al. 2019), we also experience an increased blurring of boundaries between 'natural' and 'artificial' forms of life.

In 2003, Steve Fuller and Bruno Latour debated whether 'a strong distinction between humans and non-humans is no longer required for research purposes' (Barron 2003). Two decades later, their debate has become 'embodied' in various artificial intelligences. Algorithmic online celebrities, such as Miquela Sousa aka Lil Miquela $^{1}$ with over 2 million followers on Instagram, are examples of uncanny postdigital developments, targeting children and teen audiences. Lil Miquela exhibits a fascinating array of activities and encounters. She is designed to be a celebrity 'musician,' and her activities look real(ish), suggestive of a physically attractive young person with a wealthy and 'cool' lifestyle.

Lil Miquela's 'coolness' reinforces youth pining for fame, money, slim body, and otherworldly beauty. Yet Lil Miquela is merely a digitally created avatar designed to promote various (mostly fashion) brands. She is a digital humanoid fantasy, a promotional bot, an algorithm of desire. Devised to influence online and offline, 'real' and 'fake' at the same time, Lil Miquela is an 'embodiment' of machine behaviorism (Knox, Williamson, and Bayne 2020) and postdigital living. Referring to Lil Miguela's influence on her legion of followers, Linda Papadopolous (in Booth 2019) stresses that 'this in-between thing can be very difficult for children' as 'a child needs role models but these role models are being created by marketeers'. Advertising has always created

${ }^{1}$ See https://www.instagram.com/lilmiquela/?hl=en. Accessed 2 May 2020.

Nataša Lacković

n.lackovic@lancaster.ac.uk

1 University of Lancaster, Lancaster, UK 
role models, but Lil Miquela is very different from her historical counterparts. So how should we treat Lil Miquela and her postdigital life?

Much before the 'birth' of Lil Miquela, Stuart and Elizabeth Ewen published Channels of desire: Mass Images and the Shaping of American Consciousness (Ewen and Ewen 1992). The authors discuss consumption as a way of life, followed by concepts and images that support the cultures of media-market machinery in the Western society: choice, violence, sex, and ignorance. They argue that the main purpose of media is to create and maintain human desire (to buy or behave in intended ways) by means of images. Ewen and Ewen's (1992) evoke Plato's parable of the cave. In their interpretation the world is a cave, humans live and think within that cave, and media are the shadows on the wall of that cave. Boundaries between shadows and bodies casting the shadows become blurred, yet the fascination with and belief in shadow images remain. This is a reminder that we need to think about the functioning of images, and the need for critical media literacy, in and for our postdigital and posttruth age (Lacković 2020).

Ewen and Ewen (1992) argue that the modern fascination with the external image and representation started with the industrial revolution and can be traced to an early media-orchestrated fake news event: the Great Moon Hoax of 1835 . Working as a reporter for the New York Sun, Richard Adams Locke published lithographed images claiming that they were the images of the Moon taken by the notable astronomer, Sir John Herschel, from his observatory in the Cape of Good Hope in Southern Africa. Among phantasmagorical details, Locke's article contained precise technical descriptions of the telescope, mixing credible scientific and technological descriptions with fabrications. One of these lithographs, presented in Fig. 1, displays some interesting characters such as bat-people and unicorns. At a time, however, many people believed that the lithographs showed real life on the Moon.

Human propensity to visual fascination and influence can be assigned to the historical development of common, uniformed patterns of perceiving that can lead to

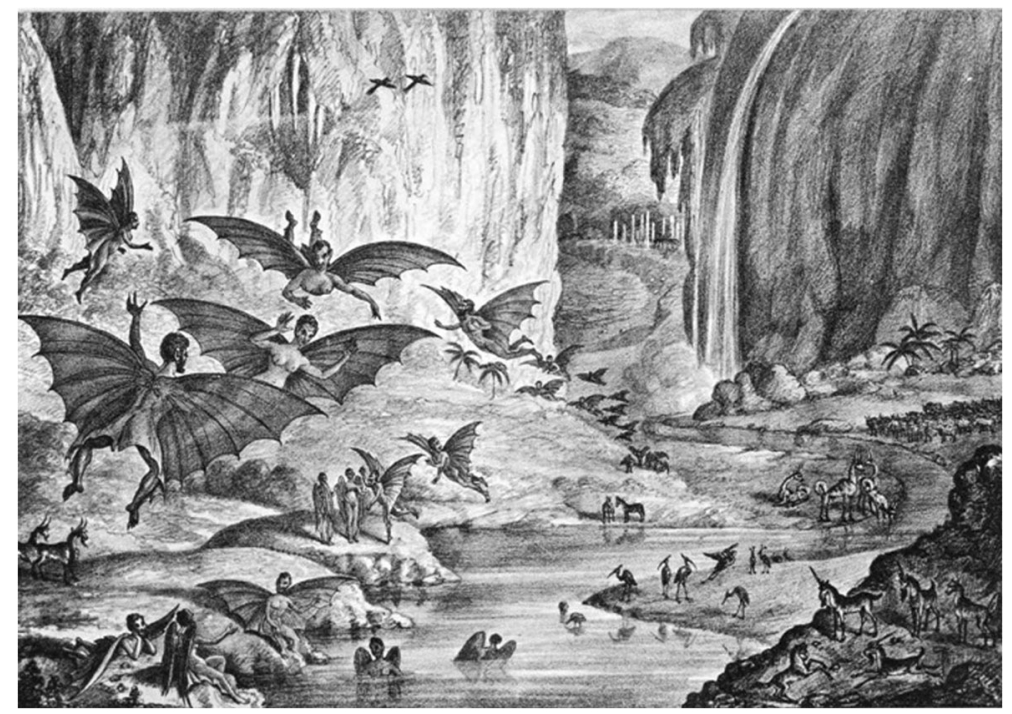

Fig. 1 A lithograph of the Great Moon Hoax's 'ruby amphitheater' (New York Sun 1835) 
believing. In a market society propelled by the industrial age, 'worlds beyond the immediate experience were of increasing relevance to people's lives,' hence, 'the media provided a powerful lens through which this broader universe might be seen and interpreted' (Ewen and Ewen 1992: 191). Fast forward to Lil Miquela, and we are presented with a brand-new species of channels of desire, a postdigital channel of desire, which is 'embodied' in algorithms of desire, targeting the most vulnerable of users.

Today's algorithms of desire are very different from 1830s lithographs or 1980s mass media, as they operate beyond classical visual regimes and play with reality in technologically sophisticated ways. Algorithms of desire may feed humans' desire for other worlds, but should also alert us to the agendas of their makers (in the case of Lil Miquela, one such obvious agenda is the sale of fashion and music products, but there is a whole world-to-desire being sold via this channel). Today they feed the desire for new socks and fancy tops, tomorrow it might be a new war.

\section{References}

Ayers, J. W., Althouse, B. M., Leas, E. C., Dredze, M., \& Allem, J. P. (2017). Internet searches for suicide following the release of 13 reasons why. JAMA Internal Medicine, 177(10), 1527-1529. https://doi. org/10.1001/jamainternmed.2017.3333.

Barron, C. (2003). A strong distinction between humans and non-humans is no longer required for research purposes: A debate between Bruno Latour and Steve fuller. History of the Human Sciences, 16(2), 77-99.

Berghel, H. (2018). Malice domestic: The Cambridge analytica dystopia. Computer, 5, 84-89. https://doi. org/10.1109/MC.2018.2381135.

Booth, R. (2019). Fake online influencers a danger to children, say campaigners. The Guardian, 4 November. https:/www.theguardian.com/media/2019/nov/04/fake-online-influencers-a-danger-to-children-saycampaigners. Accessed 2 May 2020.

Ewen, S., \& Ewen, E. (1992). Channels of desire. Mass images and the shaping of American consciousness. Minneapolis, MN: University of Minnesota Press.

Jandrić, P., Ryberg, T., Knox, J., Lacković, N., Hayes, S., Suoranta, J., et al. (2019). Postdigital dialogue. Postdigital Science and Education, 1(1), 163-189. https://doi.org/10.1007/s42438-018-0011-x.

Jones, K. (2020) How COVID-19 has impacted media consumption, by generation. Visual Capitalist, 7 April. https://www.visualcapitalist.com/media-consumption-covid-19/. Accessed 2 May 2020.

Knox, J., Williamson, B., \& Bayne, S. (2020). Machine behaviourism: Future visions of 'learnification' and 'datafication' across humans and digital technologies. Learning, Media and Technology, 45(1), 31-45. https://doi.org/10.1080/17439884.2019.1623251.

Lacković, N. (2020). Thinking with digital images in the post-truth era: A method in critical media literacy. Postdigital Science and Education, 2(2), 442-462. https://doi.org/10.1007/s42438-019-00099-y.

Mathew, B., Dutt, R., Goyal, P., \& Mukherjee, A. (2019). Spread of hate speech in online social media. In Proceedings of the 10th ACM conference on web science (pp. 173-182), New York: Association for Computing Machinery. https://doi.org/10.1145/3292522.3326034.

New York Sun (1835). File:Great-Moon-Hoax-1835-New-York-Sun-lithograph-298px.jpg. New York Sun, 28 August. https://commons.wikimedia.org/wiki/File:Great-Moon-Hoax-1835-New-York-Sunlithograph-298px.jpg. Accessed 2 May 2020. 